\title{
Autoimmune liver diseases, hepatocellular carcinoma, and recurrence of autoimmunity post- liver transplantation
}

\author{
Sarah Wang, Victor Dong, Aldo J. Montano-Loza, Andrew L. Mason \\ Division of Gastroenterology and Liver Unit, University of Alberta, Edmonton T6G 2X8, Canada. \\ Correspondence to: Prof. Andrew L. Mason, Division of Gastroenterology, 7-142 KGR, University of Alberta, 116 St \& 85 Ave, \\ Edmonton T6G 2E1, Canada. E-mail: andrew.mason@ualberta.ca
}

How to cite this article: Wang S, Dong V, Montano-Loza AJ, Mason AL. Autoimmune liver diseases, hepatocellular carcinoma, and recurrence of autoimmunity post-liver transplantation. Hepatoma Res 2021;7:42. https://dx.doi.org/10.20517/23945079.2020 .163

Received: 20 Dec 2020 First Decision: 19 Feb 2021 Revised: 4 Mar 2021 Accepted: 15 Mar 2021 Published: 11 Jun 2021

Academic Editors: Geoff McCaughan, James Fung Copy Editor: Yue-Yue Zhang Production Editor: Yue-Yue Zhang

\begin{abstract}
Liver transplantation for the autoimmune liver diseases (AILD), which includes autoimmune hepatitis (AIH), primary biliary cholangitis (PBC), and primary sclerosing cholangitis (PSC), is indicated in the setting of decompensated cirrhosis, liver failure, and hepatocellular carcinoma (HCC). The risk of HCC is thought to be low in AILD, though data on the risk factors and predictors of HCC are limited in this population. Recurrence of AILD can occur in over half of the patients, complicating the post-transplant course. The pathogenesis of recurrent AILD involves a complex interaction of genetic and environmental influences, as well as a variety of clinical risk factors. Graft and patient survival are negatively impacted by recurrent AILD and the optimal approach to the treatment of AILD recurrence is the subject of ongoing research. This review will address the current literature on the risk of HCC in AILD, as well as the development and management of recurrent AILD post-liver transplantation.
\end{abstract}

Keywords: Recurrence, autoimmune hepatitis, primary biliary cholangitis, primary sclerosing cholangitis, hepatocellular carcinoma

\section{INTRODUCTION}

Autoimmune liver diseases (AILD) that include autoimmune hepatitis (AIH), primary biliary cholangitis (PBC), and primary sclerosing cholangitis (PSC), are a common indication for liver transplantation 
worldwide $^{[1,2]}$. The need for liver transplantation (LT) in AILD is similar to liver diseases of other etiologies. This includes complications of decompensated cirrhosis and liver failure, as well as hepatocellular carcinoma $(\mathrm{HCC})^{[1,3,4]}$. Over the years, the proportion of patients requiring LT has remained stable for AIH and $\mathrm{PSC}^{[1]}$. Despite the rising prevalence of $\mathrm{PBC}$, transplantation rates have decreased over the past decades due to the widespread use of ursodeoxycholic acid (UDCA) ${ }^{[5,6]}$. In general, outcomes post-LT are favorable for patients with $\mathrm{AIH}, \mathrm{PBC}$, and PSC, with 5-year survival rates of approximately $70 \%-80 \% \%^{[1,2]}$.

The post-LT course of AILD may be complicated by recurrence of the disease. Recurrence rates of AILD have been reported anywhere from $10 \%$ to over $50 \%$ of patient ${ }^{[2,7]}$. Determining the optimal approach to studying recurrent AILD post-LT can be challenging, as studies often contain differences in diagnostic criteria, liver biopsy protocols, and follow-up times. While initial studies failed to find differences in outcomes for those with and without disease recurrence, more recent data suggest that recurrence of AILD post-LT impacts adversely on graft and overall survival ${ }^{[2]}$. Hence, AILD recurrence post-LT signifies a clinically important phenomenon that requires prompt identification and treatment.

As HCC is one of the possible LT indications in AILD, it is feasible that disease recurrence may serve as an ongoing risk factor for HCC recurrence, adding to the complexity of post-LT management. Currently, the development of HCC in AILD is thought mainly to occur in the setting of cirrhosis ${ }^{[8-10]}$. Data on the recurrence of HCC post-LT and its corresponding risk factors are lacking in patients with underlying AILD but presumably relate to the presence of extrahepatic HCC before LT.

This review will address the risk factors for HCC in AILD, and the current understanding of the pathogenesis, risk factors, and management strategies for recurrence of AILD post-LT.

\section{AUTOIMMUNE LIVER DISEASES AND THE RISK OF HEPATOCELLULAR CARCINOMA}

Hepatocellular carcinoma is the sixth most common malignancy worldwide and the third most common cause of cancer-related death ${ }^{[1,12]}$. The majority of HCC develops in the setting of cirrhosis or liver inflammation ${ }^{[11]}$. The incidence of HCC is believed to vary depending on the underlying cause of liver disease. In one meta-analysis examining the development of HCC in various etiologies of cirrhosis, chronic hepatitis B (HBV), hepatitis C (HCV), and alcohol-related liver disease (ALD) were found to have the highest risk for HCC compared to other causes, including AILDs ${ }^{[\rho]}$. A single center study in Toronto, Canada found similar results, with incidence per 1000 person years of 26.2, 21.8, and 18.4 for HBV, HCV, and ALD cirrhosis, respectively ${ }^{[13]}$. Furthermore, in keeping with the changing landscape of cirrhosis etiology, a recent study identified nonalcoholic fatty liver disease as the fastest growing cause for HCC development among patients listed for liver transplant in the United States ${ }^{[9,13,14]}$.

According to a recent meta-analysis, the incidence of HCC in AIH is 3.06 per 1000 person-years ${ }^{[15]}$ [Table 1]. Cirrhosis is the predominant risk factor for the development of HCC, with an incidence rate of 10.07 per 1000 person-years in patients with AIH cirrhosis. Other risk factors associated are older age, increased frequency of relapses, concurrent alcohol consumption, and a trend for male $\operatorname{sex}^{[15-20]}$. Asian populations are also observed to have an increased incidence of HCC, suggesting an influence of genetic and environmental factors ${ }^{[15]}$.

The risk of HCC in PBC appears to be higher than that of $\mathrm{AIH}^{[9,13]}$. According to a recent meta-analysis, the incidence of HCC in PBC is about 4.17 per 1000 person-years. Cirrhosis is a major risk factor, with an incidence rate of 15.7 per 1000 person-years. Male sex is also associated with an increased risk of HCC development in PBC, with an incidence of 9.82 per 1000 person-year ${ }^{[21]}$. The Global PBC group reported 
Table 1. Incidence and risk factors for HCC in autoimmune liver disease

\begin{tabular}{|c|c|c|}
\hline & Incidence & Risk factors \\
\hline $\mathrm{AlH}$ & 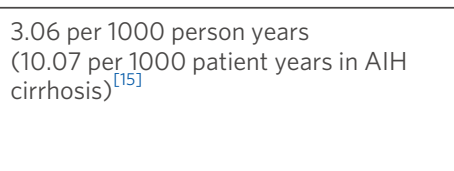 & $\begin{array}{l}\text { Cirrhosis }^{[15,16,18]} \\
\text { Older age }{ }^{[15,34,35]} \\
\text { Increased number of relapses } \\
\text { Alcohol }^{[15,34]} \\
\text { Ethnicity }^{[15,34]}\end{array}$ \\
\hline PBC & 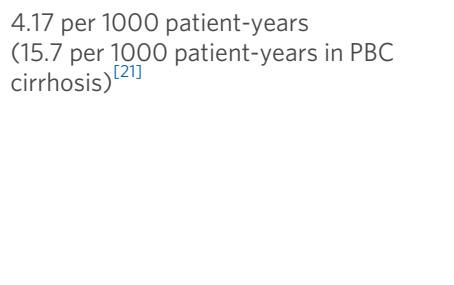 & $\begin{array}{l}\text { Cirrhosis, advanced biochemical or } \\
\text { histologic disease } \mathrm{e}^{[21,22,24,25]} \\
\text { Male }{ }^{[22,24,26,27]} \\
\text { Older Age }{ }^{[26,27]} \\
\text { Thrombocytopenia }{ }^{[22]} \\
\text { Low albumin }^{[22]} \\
\text { Incomplete response to treatment }^{[22} \\
\text { Hepatic Decompensation }^{[22]} \\
\text { Alcohol }^{[26]}\end{array}$ \\
\hline PSC & $\begin{array}{l}\text { Unknown ( } 7.2 \text { per } 1000 \text { patient-years in } \\
\text { PSC cirrhosis in one study) })^{[13]}\end{array}$ & Unknown \\
\hline
\end{tabular}

that the risk factors for HCC include advanced disease, thrombocytopenia, hepatic decompensation, and non-response to $\mathrm{UDCA}^{[22]}$. In addition, older age, low albumin, and alcohol use are associated with increased risk of HCC in $\mathrm{PBC}^{[23-27]}$.

The incidence of HCC in PSC is less well established. While PSC has a well-recognized risk of hepatobiliary malignancies, with cholangiocarcinoma developing in $13 \%$ of patients, the incidence of HCC in PSC is believed to be $\mathrm{low}^{[8,28]}$. In a retrospective study from Germany including 509 patients who were studied for 292 person-years, HCC was not observed in any patients, even though 109 patients had cirrhosis ${ }^{[29]}$. In contrast, a Canadian study assessing PSC patients with cirrhosis found that the incidence of HCC was 7.2 per 1000 patient-years ${ }^{[13]}$. Differences in these observations may be related to the severity of liver disease in the population or local factors such as variance in the transplantation rates, which can serve as a competing risk.

Currently, the American Association for the Study of Liver Diseases (AASLD) recommends screening for HCC once the annual risk exceeds $1.5 \%$, based on studies of cost-effectiveness ${ }^{[30-32]}$. As different studies are subject to heterogeneity, clinical tools have been developed to better predict the risk of HCC in various disease entities. One of these tools is the Toronto HCC Risk Index (THRI) that relies on age, etiology, gender, and platelet count to calculate a score. THRI was validated to predict HCC risk in a variety of liver diseases, including AIH, PBC, and $\mathrm{PSC}^{[13]}$. However, further research will be required to determine whether clinical risk statistical tools can change screening practices in patients with relatively low risk for HCC, as observed in AILD.

Predictors of HCC recurrence post LT are most attributable to tumour-related factors pre-LT, such as size, number, and alpha-feto-protein level ${ }^{[33]}$. However, specific risk factors for recurrent HCC in AILD are unknown. Immunosuppression is thought to play a role in the pathophysiology of HCC recurrence postLT, where more potent immunosuppression may prevent the early detection of residual HCC cells, and sirolimus is thought to have anti-proliferative activity ${ }^{[33-35]}$. In AILD, where the use of immunosuppression may influence the risk of recurrent AILD, there are no data to indicate which immunosuppression regimens may limit HCC recurrence. 


\section{AUTOIMMUNE HEPATITIS}

Autoimmune hepatitis is a chronic inflammatory liver disease characterized by elevated aminotransferases, immunoglobulin G (IgG), specific autoantibodies, and interface hepatitis on histology ${ }^{[36]}$. The annual incidence of AIH varies from 0.67 to 2.0 per 100,000 depending on the geographical region and ethnic background $^{[37-39]}$. As with most autoimmune diseases, AIH has a female preponderance. Type I AIH comprises $80 \%$ of all cases and is defined by the presence of anti-nuclear antibodies, anti-actin, or both. Type $2 \mathrm{AIH}$ is more commonly present in children and is associated with Type 1 liver-kidney microsomal antibodies (anti-LKM) and/or antibodies against liver cytosol antigen Type 1 (anti-LC1) ${ }^{[40]}$. The first-line treatment of AIH consists of corticosteroids and azathioprine, where a biochemical response may be achieved in approximately $80 \%$ of patients ${ }^{[1]}$.

\section{AlH and liver transplantation}

AIH accounts for approximately $4 \%-6 \%$ of LT in the United States and 3\% in Europe ${ }^{[41]}$. Approximately $10 \%-20 \%$ of patients with AIH will require LT in their lifetime ${ }^{[42]}$. The indication for LT in AIH is similar to other liver diseases and includes acute liver failure, complications of end-stage liver disease, and HCC meeting standardized criteria.

Unlike PSC or PBC, AIH may present as acute liver failure not responding to medical therapy. Furthermore, an increased risk of LT is associated with a lack of early response to corticosteroids ${ }^{[43]}$. A higher rate of non-response to corticosteroids is associated with a younger age at diagnosis, an acute presentation, higher bilirubin, a Model for End Stage Liver Disease (MELD) score greater than 12 at diagnosis, and the presence of HLA DRB $1{ }^{*} 03^{[44]}$. For patients presenting with jaundice, failure of the MELD score to improve after 7 days is another predictor of corticosteroid treatment failure ${ }^{[45]}$. Accordingly, early triage of non-response to treatment is important to identify with acute AIH for patients who may progress to acute liver failure and require an urgent LT workup. One recent retrospective study reported that patients with acute AIH presenting with an elevated International Normalized Ratio (INR) and bilirubin at 2 weeks was predictive of a need for LT within 12 months ${ }^{[46]}$. In patients with acute liver failure secondary to AIH, LT remains the optimal treatment, even though up to a third of patients may respond to corticosteroids initially $y^{[4,47]}$.

Outcomes in AIH post-LT are favorable, with 5- and 10-year survival rates at 90\% and 75\%, respectively; and graft survival rates are $84 \%$ and $72 \%$ at 1 and 5 years, respectively ${ }^{[4]}$. However, some reports suggest that patients who undergo transplantation for AIH are at increased risk of acute and chronic rejection ${ }^{[4,50]}$. The interaction between auto- and alloimmunity remains poorly understood and the impact on long-term outcomes warrants further investigation.

\section{Incidence and diagnosis of AlH recurrence}

Recurrent AIH (rAIH) is reported in the range of $36 \%-68 \%$ after 5 years ${ }^{[51]}$ [Table 2]. Variable frequencies are observed owing to the differences in diagnostic criteria, small sample sizes, the performance of perprotocol or event-driven biopsies, and length of follow up. The average time to recurrence is 4.6 years, with rAIH diagnosed typically more than 12 months post-LT ${ }^{[52,53]}$. Recurrence rates also tend to increase with time $e^{[2,54]}$.

The diagnosis of rAIH is challenging due to the lack of specific biomarkers and validated scoring systems in the post-LT population. Recurrent AIH is currently identified using the same criteria for AIH in patients without LT. This is based on a combination of elevated aminotransferases, IgG, the persistence of autoantibodies, consistent histological findings, exclusion of alternative diagnosis such as viral infection or 
Table 2. Incidence, diagnosis, risk factors, and management of recurrent autoimmune liver diseases post-liver transplantation

\begin{tabular}{|c|c|c|c|c|}
\hline & Incidence & Diagnosis & Risk factors & Management \\
\hline $\mathrm{rAIH}$ & $\begin{array}{l}36 \%- \\
68 \%{ }^{[51]}\end{array}$ & $\begin{array}{l}\text { Elevated transaminases/IgGs/auto-antibodies, } \\
\text { histologic features of portal inflammation with mononuclear cells, interface hepatitis, central } \\
\text { perivenulitis, and focal necrosis, } \\
\text { exclusion of alternative diagnosis such as viral infection or rejection, response to } \\
\text { steroids }^{[54,55-55,57,58]}\end{array}$ & $\begin{array}{l}\text { Concomitant autoimmune disease } \\
\text { High } A S T / A L T \text {, and } \lg G^{[66]} \\
\text { Severe inflammatory activity on } \\
\text { histology } \\
{\text { HLA DRB } D 1^{\star} 03^{[53,63]}}^{[53,68]}\end{array}$ & Corticosteroid and/or azathioprine, or $\mathrm{MMF}^{[51]}$ \\
\hline rPBC & $\begin{array}{l}21 \text { to } \\
43 \%{ }^{[91]}\end{array}$ & Liver enzyme elevation, histology showing granulomatous destruction of interlobular duct ${ }^{[96,97]}$ & $\begin{array}{l}\text { Extremes of age } e^{[100,114]} \\
\text { Biochemical cholestasis within the first } 12 \\
\text { months }{ }^{[100]} \\
\text { Immunosuppression: } \\
\text { Cyclosporine use decreased risk as } \\
\text { compared to tacrolimus } \\
\text { Genetic predisposition }{ }^{[108]} \\
\text { Increased donor age, warm and cold } \\
\text { ischemic time }{ }^{[109,11,114]}\end{array}$ & $\begin{array}{l}\text { Preventative use of UDCA, and in combination with } \\
\text { cyclosporine, post } L T \text { reduced the risk of } \mathrm{rPBC} C^{[115]}\end{array}$ \\
\hline rPSC & $\begin{array}{l}20 \% \text { to } \\
25 \%{ }^{[2]}\end{array}$ & $\begin{array}{l}\text { Diagnosis of PSC prior to LT and cholangiography showing non-anastomotic intrahepatic } \\
\text { and/or extrahepatic bile duct strictures with irregularities and beading occurring more than } 90 \\
\text { days post-LT } \\
\text { Or } \\
\text { Liver biopsy demonstrating fibrous cholangitis and/or fibro-obliterative lesions }{ }^{[127]}\end{array}$ & $\begin{array}{l}\text { Inflammatory bowel disease } \mathrm{e}^{[128-130]} \\
\text { Acute cellular rejection }{ }^{[1313,132,134,135]} \\
\text { Donor-recipient CMV mismatch }{ }^{[133]} \\
\text { Poor graft quality }{ }^{[133]} \\
\text { Pre-transplant MELD }>24^{[133,135]} \\
\text { Cholangiocarcinoma } a^{[134,135]} \\
\text { Higher donor age }{ }^{[134]}\end{array}$ & $\begin{array}{l}\text { No proven therapies } \\
\text { Symptomatic management }\end{array}$ \\
\hline
\end{tabular}

ALT: Alanine aminotransferase; AST: aspartate transaminase; CMV: cytomegalovirus; MELD: model for end stage liver disease; MMF: mycophenolate mofetil; UDCA: ursodeoxycholic acid.

rejection, and response to steroids ${ }^{[5,55]}$. The presence of autoantibodies is in itself not a marker of rAIH, as many patients continue to have persistence of antibodies post-LT ${ }^{[56]}$. Histological findings typically consist of portal inflammation with mononuclear cells, particularly plasma cells, interface hepatitis, central perivenulitis, and focal necrosis ${ }^{[5,57,58]}$. One study reported that histologic findings of $\mathrm{rAIH}$ can occur before the onset of biochemical abnormalities if protocolized liver biopsies are performed ${ }^{[59]}$.

\section{Pathogenesis and risk factors for AlH recurrence}

The pathogenesis for AIH recurrence is unknown largely because the etiology of AIH is poorly understood. Some have proposed that recipient memory T-cells recognize auto-antigenic peptides on mismatched HLA donor graft ${ }^{[3]}$, while others have questioned whether this process occurs in the setting of potent immunosuppression post-LT ${ }^{[60]}$. One explanation is that suppression of regulatory $\mathrm{T}$ cells occurs under the influence of immunosuppression, causing immune dysregulation ${ }^{[61]}$. However, alternative hypotheses have been proposed in studies showing an increased risk of rAIH with corticosteroid withdrawal and the association of long-term steroid with a lower incidence of $\mathrm{rAIH}^{[62-65]}$. Despite continued corticosteroid use, it is still notable that patients with rAIH and "normal" liver tests may still progress to cirrhosis. The type and strength of immunosuppression may play a role, but current data on the effect of specific 
pharmacologic agents and disease recurrence are lacking.

The severity of inflammatory activity pre-transplant is correlated with an increased risk of rAIH. For example, we found that concomitant autoimmune disease, high aspartate transaminase/alanine transaminase, and IgG are associated with an increased risk of recurrence post-LT ${ }^{[66]}$. Histological evidence of severe inflammatory activity in the native liver is also associated with an elevated risk of $\mathrm{rAIH}^{[6,67]}$. Others have reported that the known risk factor HLA DRB $1^{*} 03$ is more commonly found in patients with recurrence ${ }^{[53,68]}$. This led to the conclusion that donor-recipient mismatch may affect recurrence or graft survival, but the evidence is inconsistent. A few reports have demonstrated mismatch of HLA status increased graft survival in $\mathrm{AIH}^{[69,70]}$, while other studies have not ${ }^{[6,77]}$. The role of HLA remains a mystery in the development of $\mathrm{rAIH}$ and a better understanding of the process in the non-transplant setting would help in understanding the pathogenesis of disease recurrence.

\section{Management and outcomes of AlH recurrence}

Graft failure occurs in $13 \%$ to $50 \%$ of patients with $\mathrm{rAIH}^{[5,63]}$. Compared to other liver diseases, $\mathrm{rAIH}$ is associated with a higher risk of graft loss and an increased risk of death from liver failure ${ }^{[72,73]}$. Retransplantation is performed for pediatric and young adult patients with progressive liver failure from $\mathrm{rAIH}^{[2]}$. Treatment of AIH recurrence depends on the clinical presentation and severity of the disease. In most cases, optimizing immunosuppression with corticosteroid and/or azathioprine can induce and maintain disease remission [Figure 1] ${ }^{[51]}$. In treatment failure, other immunosuppressive agents, such as mycophenolate mofetil (MMF), or sirolimus are found to have some benefit in rAIH management ${ }^{[54,74]}$. The role of preventative corticosteroid use is controversial because a meta-analysis failed to demonstrate a benefit of continuous steroids on graft survival, rejection rates, $\mathrm{rAIH}$, and patient survival ${ }^{[51]}$. Accordingly, the current AASLD guidelines suggest discontinuing corticosteroids post LT and monitoring for $\mathrm{rAIH}^{[51]}$.

\section{PRIMARY BILIARY CHOLANGITIS}

Primary biliary cholangitis (PBC) is a cholestatic autoimmune liver disease characterized by chronic, destructive non-suppurative granulomatous cholangitis of the small and medium-sized intrahepatic bile ducts ${ }^{[75]}$. The disease is rare, with an incidence reported to be approximately 0.7 to 49 per million per year, and predominantly affects women, with a 10:1 female preponderance ${ }^{[5,76]}$. PBC is distinguished serologically by the presence of anti-mitochondrial antibodies (AMA) reactive to pyruvate dehydrogenase complex (PDC)-E2 that is found in over $80 \%$ of patients with $\mathrm{PBC}^{[76]}$. Notably, PDC-E2 is aberrantly expressed on the surface of cholangiocytes and this is thought to lead to the loss of tolerance to self with the expression of $\mathrm{AMA}^{[77]}$.

The pathogenesis of $\mathrm{PBC}$ is complex and it is thought that an environmental agent(s) may trigger disease in a genetically susceptible host ${ }^{[78]}$. Genomic studies have implicated variants in HLA class II and the interleukin 12 pathway in the development of $\mathrm{PBC}^{[78,79]}$. Potential triggers theorized to induce an autoimmune response in $\mathrm{PBC}$ include xenobiotics, drugs, bacteria, and viruses ${ }^{[80]}$. Of these agents, only the human betaretrovirus has been shown to trigger the PBC phenotype of increased PDC-E2 expression in cholangiocytes ${ }^{[81]}$. The role of autoimmunity in the development of PBC is questionable because the loss of tolerance to mitochondrial proteins has not been experimentally shown to trigger cholangitis, and immunosuppression does not provide benefit for preventing the disease progression ${ }^{[80]}$.

The first-line management of PBC is UDCA, which has been shown to improve liver transplant-free survival ${ }^{[82]}$. For those not achieving adequate response to UDCA, the second line therapy includes the addition of obeticholic acid and bezafibrate, which may also serve to manage pruritus as well ${ }^{[83-86]}$. 

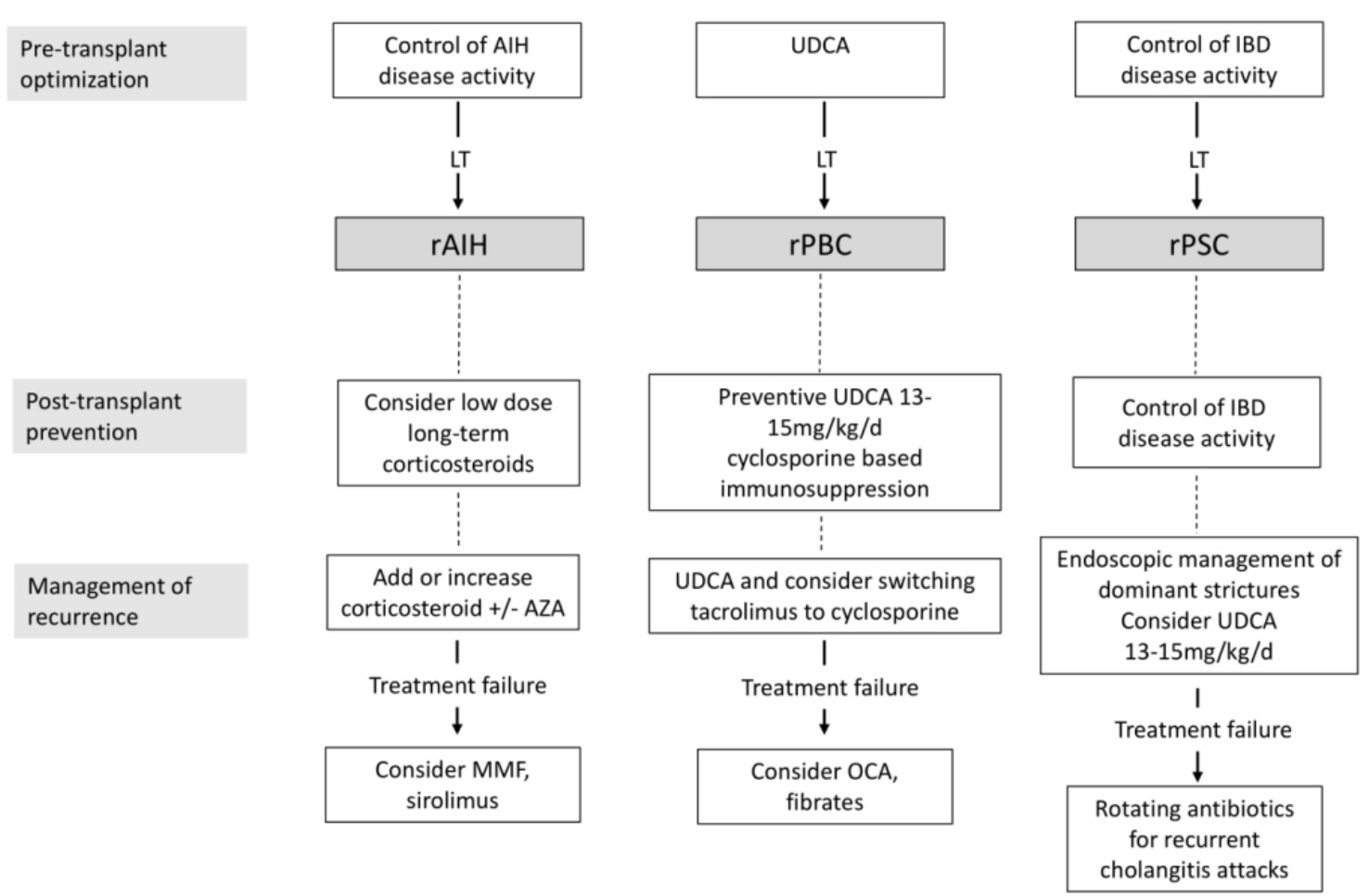

Figure 1. Prevention and treatment of AILD recurrence post LT. AZA: Azathioprine; IBD: inflammatory bowel disease; MMF: mycophenolate mofetil; OCA: obeticholic acid; UDCA: ursodeoxycholic acid.

\section{PBC and liver transplantation}

Overall, liver transplantation for PBC has decreased by $20 \%$ in the US from 1996 to 2006, despite an increasing prevalence of $\mathrm{PBC}$ and this is attributable to improved disease management with UDCA ${ }^{[8788]}$. Several risk scores incorporating improvement in alkaline phosphatase and bilirubin on UDCA therapy have been validated to predict LT-free survival ${ }^{[89]}$. The indication for LT in PBC is similar to other liver diseases and also includes those with intractable severe pruritus as the sole indication for $\mathrm{LT}^{[00,91]}$. Although the severity of fatigue may be extreme in $\mathrm{PBC}$, it is not a standalone indication for LT especially because the symptom may not necessarily improve post- $\mathrm{LT}^{[92,93]}$. Rarely, non-cirrhotic patients who suffer from complications of presinusoidal portal hypertension may require $\mathrm{LT}^{[94]}$.

Outcomes after LT for PBC are excellent. Patient survival at 1 and 5 years ranges from 83\%-93\% and 77\%$86 \%$ and graft survival at 1 and 5 years ranges from $79 \%-88 \%$ and $71 \%$ to $84 \%^{[48,95]}$.

\section{Incidence and diagnosis of $\mathrm{PBC}$ recurrence}

The incidence of recurrent PBC ( $\mathrm{rPBC})$ is approximately $21 \%-37 \%$ at 10 years and $43 \%$ at 15 years ${ }^{[9]]}$. The median time to recurrence is between 3 to 5.5 years $^{[96]}$. As observed with $\mathrm{rAIH}$, the difference in reported recurrence rates is related to the variable histologic criteria, use of protocol biopsies, and length of follow up between centers. The diagnosis of $\mathrm{rPBC}$ is typically based on histology, where granulomatous destruction of the interlobular duct is a pathognomonic finding. Less specific but more sensitive histological features include moderate lymphocytic cholangitis and dense lymphoplasmacytic infiltrate ${ }^{[06,97]}$. Liver enzymes may be normal or minimally elevated even in the presence of histologic abnormalities ${ }^{[97,98]}$. Serum AMA does not appear to correlate with PBC recurrence ${ }^{[98,99]}$. 


\section{Pathogenesis and risk factors for $\mathrm{PBC}$ recurrence}

The pathogenesis of $\mathrm{rPBC}$ is poorly understood. The development of cholestatic liver tests in the first year following LT signals the subsequent development of $\mathrm{rPBC}^{[100]}$. We have argued that this is more in keeping with an infectious disease process as autoimmunity would be an unlikely cause of pathology early on when immunosuppression levels are highest. Recurrent disease also occurs with evidence of the PBC phenotype of PDC-E2 expression in the allograft. One report documented close to $70 \%$ of patients with serum AMA and aberrant expression of PDC-E2 in cholangiocytes, whereas less than 30\% of patients had histological evidence of $\mathrm{rPBC}^{[101]}$. Another pathological process that signals the subsequent occurrence of $\mathrm{rPBC}$ is epithelial mesenchymal transition in cholangiocytes that predates discernable histological changes of $\mathrm{rPBC}^{[102]}$. This developmental pathway may be driven by Wnt transcription factors, which have been identified in PBC liver in microarray studies ${ }^{[103]}$. A commonality in the development of Wnt signaling and PDC-E2 expression in cholangiocytes is betaretrovirus infection, but this has not been directly implicated in $\mathrm{rPBC}^{[81]}$.

The role of HLA in the development of rPBC is debatable. One Japanese study involving living donor transplant recipients showed that HLA matching is associated with increased risk of $\mathrm{rPBC}^{[104]}$ but this was not confirmed in other studies ${ }^{[105]}$. Similarly, studies including deceased donors reported conflicting results concerning the role of HLA as well ${ }^{[71,96,10,107]}$. A study from the United Kingdom reported that the risk of $\mathrm{rPBC}$ differed based on varying single nucleotide polymorphisms at the IL12A locus. The highest risk of rPBC was associated with rs62270414 genotype AG or GG, and the lowest risk was observed in those with the rs62270414 genotype $\mathrm{AA}^{[108]}$. In this study, the use of cyclosporine versus tacrolimus was found to be protective $^{[108]}$.

The use of other immunosuppressive agents like azathioprine and MMF and their relationship with rPBC are more difficult to interpret. In the era from the mid-1980s to the mid-1990s, azathioprine was used in conjunction with both cyclosporine and tacrolimus, so the risk attributable to azathioprine is uncertain $^{[107,109]}$. As reported in most series, the type of immunosuppression appears to influence recurrent disease. In a large multicenter study of $785 \mathrm{LT}$ recipients with $\mathrm{PBC}$, the use of tacrolimus was a major risk factor for $\mathrm{rPBC}$, whereas cyclosporine was protective $\mathrm{e}^{[100]}$. This has been a recurrent finding that cyclosporine use correlates with decreased risk of $\mathrm{rPBC}$ and a prolonged interval to develop rPBC as compared to tacrolimus ${ }^{[107,110-112]}$. While the mechanisms that modulate outcomes with different calcineurin inhibitors remain unclear, it seems likely that the increased potency of immunosuppression overall amplifies the risk of $\mathrm{rPBC}^{[113]}$. Furthermore, we have suggested that the protective effect of cyclosporine is due to the known antiviral properties and have shown that cyclosporine inhibits betaretrovirus linked with the pathogenesis of $\mathrm{PBC}^{[111]}$.

With regard to recipient risk, a younger age of diagnosis increases the chance of developing $\mathrm{rPBC}^{[100]}$. The donor factors include increased donor age, as well as warm and cold ischemic time providing an increased incidence of $\mathrm{rPBC}^{[109,112,114]}$.

\section{Management and outcomes after PBC recurrence}

As used in the pre-transplant setting, UDCA has become the first-line management for rPBC. While UDCA is associated with improved liver function tests, data on the impact on histological regression, graft function, or patient survival are limited ${ }^{[114]}$. Notably in the largest study to date, UDCA (13-15mg/kg/day) has been shown to decrease the risk graft dysfunction and death, as well as the risk of rPBC. The study also found that the use of cyclosporine had an additive effect to UDCA in reducing recurrence, graft loss, and mortality ${ }^{[115]}$. Thus, while the treatment of $\mathrm{rPBC}$ is not established, preventative UDCA and possibly the use of cyclosporine-based immunosuppression are useful strategies to prevent recurrence. Further studies are 
required to determine if second-line therapies, such as obeticholic acid, and fibrates, are effective in the management of $\mathrm{rPBC}$, especially now that it has been established that recurrence is associated with increased risk of graft loss and death ${ }^{[100]}$.

\section{PRIMARY SCLEROSING CHOLANGITIS}

Primary sclerosing cholangitis (PSC) is a progressive disease of the biliary tract characterized by inflammation and scarring of intrahepatic and extrahepatic bile ducts leading to cirrhosis ${ }^{[116]}$. The prevalence in North America ranges from 1 to 16 per 100,000 people ${ }^{[117]}$. Approximately $80 \%$ of PSC patients suffer from inflammatory bowel disease (IBD), especially ulcerative colitis ${ }^{[118]}$. PSC is usually diagnosed by demonstrating large bile duct strictures by cholangiography in the absence of other causes. Liver biopsy is not required for diagnosis and may reveal the characteristic periductal concentric "onion skin" fibrosis ${ }^{[119]}$. Currently, there are no proven therapies for PSC and the role of UDCA is uncertain ${ }^{[116]}$.

PSC is an immune-mediated disease that may occur in association with a variety of other autoimmune diseases $^{[120,121]}$. Genetic predisposition is linked with both HLA and non-HLA loci, some of which were also related to $\mathrm{IBD}^{[78,122,123]}$. Several environmental and infectious factors have been proposed to trigger the development of this disease $\mathrm{e}^{[78,117]}$. The predominance of a skewing towards a specific intrahepatic T-cell receptor V $\beta$ subset suggests the possibility of a microbial superantigen activity in PSC patients ${ }^{[124]}$.

\section{PSC and liver transplantation}

Transplantation is required for patients with PSC with life-threatening complications of cirrhosis or recurrent cholangitis ${ }^{[91]}$. In highly selected cases, LT is considered for selected patients with cholangiocarcinoma in conjunction with neoadjuvant chemotherapy ${ }^{[125]}$. On a prognostic level, patients with serum alkaline phosphatase levels greater than or equal to 2.4 times the upper limit of normal are at increased risk of $\mathrm{LT}^{[126]}$. The post-LT survival for PSC is excellent with 1-year, 3-year, 5-year, and 10-year post-LT survival rates of $93.4 \%, 89.7 \%, 87.4 \%$, and $83.2 \%$, respectively, in the United States ${ }^{[127]}$.

\section{Incidence and diagnosis of PSC recurrence}

One of the major complications post-LT is the development of recurrent PSC (rPSC). Rates of rPSC are reported to occur in $20 \%$ to $25 \%$ of patients over 10 years ${ }^{[2]}$. The diagnosis is often challenging and exclusion of other causes of biliary strictures must be ruled out. These include hepatic artery thrombosis, anastomotic strictures, non-anastomotic strictures occurring less than 90 days post-LT, donor-recipient ABO incompatibility, and chronic ductopenic rejection ${ }^{[127]}$. Diagnostic criteria of rPSC include a diagnosis of PSC prior to LT and a cholangiographic appearance of non-anastomotic intrahepatic and/or extrahepatic bile duct strictures with irregularities and beading occurring more than 90 days post-LT ${ }^{[127]}$. Some advocate the use of a diagnostic liver biopsy demonstrating concentric fibrous cholangitis and/or fibro-obliterative lesions to make a diagnosis of rPSC although this is less well-accepted ${ }^{[127]}$.

\section{Pathogenesis and risk factors for recurrent PSC}

Although many studies have examined the risk factors, it is unclear why rPSC develops post-LT. One of the main risk factors is IBD, as demonstrated with the decreased frequency of rPSC following colectomy prior to $\mathrm{LT}^{[128]}$. Others have reported that the presence of ulcerative colitis post-LT is significantly associated with the development of $\mathrm{rPSC}^{[129]}$. In those without a prior history of ulcerative colitis, the development of $d e$ novo colitis increases the risk considerably ${ }^{[130]}$. These studies underscore the importance of colonic disease post-LT and suggest that the management with either prophylactic colectomy or the treatment of IBD is protective against the development of rPSC. 
Another significant risk factor for rPSC that has been extensively studied is the occurrence of acute cellular rejection post-LT. In a North American study, for example, $71 \%$ of patients with rPSC had prior acute rejection as compared to $22 \%$ of patients without rPSC, and $29 \%$ of patients with rPSC had steroid-resistant rejection versus none of the patients without $\mathrm{rPSC}^{[131]}$. A study from the Netherlands also found that acute cellular rejection increased the frequency of $\mathrm{rPSC}^{[132]}$. Some have suggested that the link of rPSC with rejection may be inflammation of the biliary epithelium that occurs in acute cellular rejection leading to damage of the bile ducts ${ }^{[127]}$. It is equally possible that the increased use of immune suppression and immune reconstitution may influence the development of rPSC.

A multitude of other risk factors have also been identified to be predictors of rPSC. Donor-recipient cytomegalovirus mismatch was found to increase risk $^{[133]}$. Graft quality including increased donor age and extended donor criteria grafts were also identified as risk factors for rPSC development ${ }^{[133]}$. Furthermore, the severity of PSC pre-LT with a MELD score greater than 24 and increased INR at the time of LT both increase the risk of $\mathrm{rPSC}^{[133]}$.

More recently a meta-analysis reported that colectomy prior to LT, presence of IBD, cholangiocarcinoma, higher donor age, and single or multiple episodes of rejection, were all independent risk factors of developing $\mathrm{rPSC}^{[134]}$. A separate meta-analysis confirmed that cholangiocarcinoma, multiple episodes of rejection, MELD score, and use of MMF and cyclosporine for immunosuppression were significantly associated with increased risk of $\mathrm{rPSC}^{[135]}$.

\section{Management and outcomes of recurrent PSC}

There are no proven therapies for rPSC. However, we advocate judicial use of immunosuppression as cyclosporine appears protective versus tacrolimus ${ }^{[135]}$ and immune reconstitution is associated with flares in the disease process. Whereas UDCA appears to improve liver function tests, its effects on patient outcomes with rPSC are less clear ${ }^{[127]}$. Overall, symptomatic management of complications including biliary strictures, cholangitis, and pruritus, is generally the only option. The development of rPSC also significantly affects graft survival and leads to the highest risk of graft loss in patients with AILD. Retransplantation is ultimately required for $20 \%$ to $43 \%$ of patients with PSC $^{[133]}$.

\section{PROSPECTUS}

Autoimmune liver diseases are a major indication for LT worldwide. In general, while outcomes for AIH, $\mathrm{PBC}$, and PSC are favorable post-LT, recurrence of AILD is common, with reported rates varying based on diagnostic criteria and follow-up times. Currently, our lack of knowledge of AILD pathogenesis severely impacts our understanding of disease recurrence in the post-transplant setting, leading to limited effective treatments.

HCC can occur in the AILD, with cirrhosis as the major risk factor. Recurrence of AILD following transplantation for HCC may play a role in clinical outcomes, though studies on HCC recurrence in AILD are sparse. Nevertheless, recurrence of AILD has shown decreased graft and patient survival post-LT, prompting the need for improved management strategies.

In $\mathrm{AIH}$, the role of disease activity and the use of immunosuppression to control inflammation appear to contribute significantly to the development of recurrence. Future studies focused on maintaining remission with AIH, with alternative pharmacologic options for non-responders, are required to better manage recurrence in the post-transplant population. In PBC, while the beneficial role of preventative UDCA and cyclosporine is understood, future prospective studies are needed to confirm the role of second-line 
therapies on long-term outcomes. In PSC, there is a need to develop effective management strategies in both the pre-and post-LT setting.

In summary, the mechanisms that mediate recurrence of AILD post-LT are complex and a better understanding of the processes involved are required to achieve improved outcomes in patients following LT.

\section{DECLARATIONS}

\section{Authors' contributions}

Contributed to the search and selection of the articles, review of articles, conception and design of the manuscript, writing and revising of the manuscript draft, and review of the final version of the manuscript: Wang S, Dong V, Mason AL

Contributed to the selection of articles, revising of the draft, and review of the final version of the manuscript: Montano-Loza AJ.

\section{Availability of data and materials}

Not applicable.

\section{Financial support and sponsorship}

Mason AL is supported by grants from the Canadian Institutes for Health Research (PS156013).

\section{Conflicts of interest}

All authors declared that there are no conflicts of interest.

\section{Ethical approval and consent to participate}

Not applicable.

\section{Consent for publication}

Not applicable.

\section{Copyright}

(c) The Author(s) 2021.

\section{REFERENCES}

1. Carbone M, Neuberger JM. Autoimmune liver disease, autoimmunity and liver transplantation. J Hepatol 2014;60:210-23. DOI PubMed

2. Montano-Loza AJ, Bhanji RA, Wasilenko S, Mason AL. Systematic review: recurrent autoimmune liver diseases after liver transplantation. Aliment Pharmacol Ther 2017;45:485-500. DOI PubMed

3. Ilyas JA, O'Mahony CA, Vierling JM. Liver transplantation in autoimmune liver diseases. Best Pract Res Clin Gastroenterol 2011;25:765-82. DOI PubMed

4. Liberal R, Zen Y, Mieli-Vergani G, Vergani D. Liver transplantation and autoimmune liver diseases. Liver Transpl 2013;19:1065-77. DOI PubMed

5. Prince MI, James OF. The epidemiology of primary biliary cirrhosis. Clin Liver Dis 2003;7:795-819. DOI

6. Webb GJ, Rana A, Hodson J, et al. Twenty-Year Comparative Analysis of Patients With Autoimmune Liver Diseases on Transplant Waitlists. Clin Gastroenterol Hepatol 2018;16:278-87.e7. DOI PubMed

7. Tanaka A, Kono H, Leung PSC, Gershwin ME. Recurrence of disease following organ transplantation in autoimmune liver disease and systemic lupus erythematosus. Cell Immunol 2020;347:104021. DOI PubMed

8. Lleo A, de Boer YS, Liberal R, Colombo M. The risk of liver cancer in autoimmune liver diseases. Ther Adv Med Oncol 2019;11:1758835919861914. DOI PubMed PMC

9. Tarao K, Nozaki A, Ikeda T, et al. Real impact of liver cirrhosis on the development of hepatocellular carcinoma in various liver diseases-meta-analytic assessment. Cancer Med 2019;8:1054-65. DOI PubMed PMC

10. Montano-Loza AJ, Carpenter HA, Czaja AJ. Predictive factors for hepatocellular carcinoma in type 1 autoimmune hepatitis. Am $J$ Gastroenterol 2008;103:1944-51. DOI PubMed 
11. Schütte K, Bornschein J, Malfertheiner P. Hepatocellular carcinoma--epidemiological trends and risk factors. Dig Dis 2009;27:80-92. DOI PubMed

12. Ferenci P, Fried M, Labrecque D, et al. Hepatocellular carcinoma (HCC): a global perspective. J Clin Gastroenterol 2010;44:239-45. DOI PubMed

13. Sharma SA, Kowgier M, Hansen BE, et al. Toronto HCC risk index: A validated scoring system to predict 10-year risk of HCC in patients with cirrhosis. J Hepatol 2017:S0168-8278(17)32248. DOI PubMed

14. Younossi Z, Stepanova M, Ong JP, et al. Nonalcoholic steatohepatitis is the fastest growing cause of hepatocellular carcinoma in liver transplant candidates. Clin Gastroenterol Hepatol 2019;17:748-55.e3. DOI PubMed

15. Tansel A, Katz LH, El-Serag HB, et al. Incidence and determinants of hepatocellular carcinoma in autoimmune hepatitis: a systematic review and meta-analysis. Clin Gastroenterol Hepatol 2017;15:1207-17.e4. DOI PubMed PMC

16. Hino-Arinaga T, Ide T, Kuromatsu R, et al. Risk factors for hepatocellular carcinoma in Japanese patients with autoimmune hepatitis type 1. J Gastroenterol 2012;47:569-76. DOI PubMed

17. Yoshizawa K, Matsumoto A, Ichijo T, et al. Long-term outcome of Japanese patients with type 1 autoimmune hepatitis. Hepatology 2012;56:668-76. DOI PubMed

18. Migita K, Watanabe Y, Jiuchi Y, et al. Hepatocellular carcinoma and survival in patients with autoimmune hepatitis (Japanese National Hospital Organization-autoimmune hepatitis prospective study). Liver International ;2012:837-44. DOI PubMed

19. Macaron C, Hanouneh IA, Zein NN. Incidence and risk factors of hepatocellular carcinoma in patients with primary biliary cirrhosis. Hepatology 2010;52:2239; author reply 2239-40. DOI PubMed

20. Hoeroldt B, McFarlane E, Dube A, et al. Long-term outcomes of patients with autoimmune hepatitis managed at a nontransplant center. Gastroenterology 2011;140:1980-9. DOI PubMed

21. Natarajan Y, Tansel A, Patel P, et al. Incidence of hepatocellular carcinoma in primary biliary cholangitis: a systematic review and meta-analysis. Dig Dis Sci 2020. DOI

22. Trivedi PJ, Lammers WJ, van Buuren HR, et al. Stratification of hepatocellular carcinoma risk in primary biliary cirrhosis: a multicentre international study. Gut 2016;65:321-9. DOI PubMed

23. Hosonuma K, Sato K, Yanagisawa M, et al. Incidence, mortality, and predictive factors of hepatocellular carcinoma in primary biliary cirrhosis. Gastroenterol Res Pract 2013;2013:168012. DOI PubMed PMC

24. Harada K, Nakanuma Y. Prevalence and risk factors of hepatocellular carcinoma in Japanese patients with primary biliary cirrhosis. Hepatol Res 2014;44:133-40. DOI PubMed

25. Tomiyama Y, Takenaka K, Kodama T, et al. Risk factors for survival and the development of hepatocellular carcinoma in patients with primary biliary cirrhosis. Intern Med 2013;52:1553-9. DOI PubMed

26. Zhang X-X, Wang L-F, Jin L, et al. Primary biliary cirrhosis-associated hepatocellular carcinoma in Chinese patients: incidence and risk factors. World J Gastroenterol 2015;21:3554-63. DOI PubMed PMC

27. Rong G, Wang H, Bowlus CL, et al. Incidence and risk factors for hepatocellular carcinoma in primary biliary cirrhosis. Clin Rev Allergy Immunol 2015;48:132-41. DOI PubMed

28. Bergquist A, Ekbom A, Olsson R, et al. Hepatic and extrahepatic malignancies in primary sclerosing cholangitis. $J$ Hepatol 2002;36:321-7. DOI PubMed

29. Zenouzi R, Weismüller TJ, Hübener P, et al. Low risk of hepatocellular carcinoma in patients with primary sclerosing cholangitis with cirrhosis. Clin Gastroenterol Hepatol 2014;12:1733-8. DOI PubMed

30. Sarasin FP, Giostra E, Hadengue A. Cost-effectiveness of screening for detection of small hepatocellular carcinoma in western patients with Child-Pugh class A cirrhosis. Am J Med 1996;101:422-34. DOI PubMed

31. Lin OS, Keeffe EB, Sanders GD, Owens DK. Cost-effectiveness of screening for hepatocellular carcinoma in patients with cirrhosis due to chronic hepatitis C. Aliment Pharmacol Ther ;2004:1159-72. DOI PubMed

32. Arguedas MR, Chen VK, Eloubeidi MA, Fallon MB. Screening for hepatocellular carcinoma in patients with hepatitis C cirrhosis: a cost-utility analysis. Am J Gastroenterol 2003;98:679-90. DOI PubMed

33. Sapisochin G, Bruix J. Liver transplantation for hepatocellular carcinoma: outcomes and novel surgical approaches. Nat Rev Gastroenterol Hepatol 2017;14:203-17. DOI PubMed

34. Macaron C, Hanouneh I, Lopez R, Zein NN. S1883 Incidence and Risk Factors of Hepatocellular Carcinoma in Patients With Primary Biliary Cirrhosis and Autoimmune Hepatitis. Gastroenterology 2010;138:S-809. DOI

35. Hoeroldt B, MacFarlane E, Basumani P, Gleeson D. 793 HEPATOCELLULAR CARCINOMA IN AUTOIMMUNE HEPATITIS. Journal of Hepatology 2009;50:S290. DOI

36. Kerkar N, Chan A. Autoimmune hepatitis, sclerosing cholangitis, and autoimmune sclerosing cholangitis or overlap syndrome. Clin Liver Dis 2018;22:689-702. DOI PubMed

37. Ngu JH, Bechly K, Chapman BA, et al. Population-based epidemiology study of autoimmune hepatitis: a disease of older women? $J$ Gastroenterol Hepatol 2010;25:1681-6. DOI PubMed

38. Delgado J-S, Vodonos A, Malnick S, et al. Autoimmune hepatitis in southern Israel: a 15-year multicenter study. J Dig Dis 2013;14:611-8. DOI PubMed

39. Werner M, Prytz H, Ohlsson B, et al. Epidemiology and the initial presentation of autoimmune hepatitis in Sweden: a nationwide study. Scand J Gastroenterol 2008;43:1232-40. DOI PubMed

40. Czaja AJ. Diagnosis and management of autoimmune hepatitis. Clin Liver Dis 2015;19:57-79. DOI PubMed

41. Faisal N, Renner EL. Recurrence of autoimmune liver diseases after liver transplantation. World J Hepatol 2015;7:2896-905. DOI PubMed PMC 
42. Gleeson D, Heneghan MA, British Society of Gastroenterology. British Society of Gastroenterology (BSG) guidelines for management of autoimmune hepatitis. Gut 2011;60:1611-29. DOI PubMed

43. Tan P, Marotta P, Ghent C, Adams P. Early treatment response predicts the need for liver transplantation in autoimmune hepatitis. Liver Int 2005;25:728-33. DOI PubMed

44. Montano-Loza AJ, Carpenter HA, Czaja AJ. Features associated with treatment failure in type 1 autoimmune hepatitis and predictive value of the model of end-stage liver disease. Hepatology 2007;46:1138-45. DOI PubMed

45. Yeoman AD, Westbrook RH, Zen Y, et al. Early predictors of corticosteroid treatment failure in icteric presentations of autoimmune hepatitis. Hepatology 2011;53:926-34. DOI PubMed

46. Biewenga M, Inderson A, Tushuizen ME, Crobach ASLP, van Hoek B. Early predictors of short-term prognosis in acute and acute severe autoimmune hepatitis. Liver Transpl 2020;26:1573-81. DOI PubMed PMC

47. Rahim MN, Liberal R, Miquel R, Heaton ND, Heneghan MA. Acute severe autoimmune hepatitis: corticosteroids or liver transplantation? Liver Transpl 2019;25:946-59. DOI PubMed

48. Adam R, Karam V, Delvart V, et al. Evolution of indications and results of liver transplantation in Europe. A report from the European Liver Transplant Registry (ELTR). J Hepatol 2012;57:675-88. DOI PubMed

49. Milkiewicz P, Gunson B, Saksena S, Hathaway M, Hubscher SG, Elias E. Increased incidence of chronic rejection in adult patients transplanted for autoimmune hepatitis: assessment of risk factors. Transplantation 2000;70:477-80. DOI PubMed

50. Narumi S, Hakamada K, Sasaki M, et al. Liver transplantation for autoimmune hepatitis: rejection and recurrence. Transplant Proc 1999;31:1955-6. DOI PubMed

51. Mack CL, Adams D, Assis DN, et al. Diagnosis and Management of Autoimmune Hepatitis in Adults and Children: 2019 Practice Guidance and Guidelines From the American Association for the Study of Liver Diseases. Hepatology 2020;72:671-722. DOI PubMed

52. Beal EW, Black SM, Michaels A. Autoimmune Hepatitis in the Liver Transplant Graft. Clin Liver Dis 2017;21:381-401. DOI PubMed PMC

53. González-Koch A, Czaja AJ, Carpenter HA, et al. Recurrent autoimmune hepatitis after orthotopic liver transplantation. Liver Transpl 2001;7:302-10. DOI PubMed

54. Manns MP, Czaja AJ, Gorham JD, et al. Diagnosis and management of autoimmune hepatitis. Hepatology 2010;51:2193-213. DOI PubMed

55. Banff Working Group, Demetris AJ, Adeyi O, et al. Liver biopsy interpretation for causes of late liver allograft dysfunction. Hepatology 2006;44:489-501. DOI PubMed

56. Reich DJ, Fiel I, Guarrera JV, et al. Liver transplantation for autoimmune hepatitis. Hepatology 2000;32:693-700. DOI PubMed

57. Edmunds C, Ekong UD. Autoimmune liver disease post-liver transplantation: a summary and proposed areas for future research. Transplantation 2016;100:515-24. DOI PubMed PMC

58. Hübscher SG. Recurrent autoimmune hepatitis after liver transplantation: diagnostic criteria, risk factors, and outcome. Liver Transpl 2001;7:285-91. DOI PubMed

59. Duclos-Vallee J-C, Sebagh M. Recurrence of autoimmune disease, primary sclerosing cholangitis, primary biliary cirrhosis, and autoimmune hepatitis after liver transplantation. Liver Transpl 2009;15 Suppl 2:S25-34. DOI PubMed

60. O'Grady JG. Phenotypic expression of recurrent disease after liver transplantation. Am J Transplant 2010;10:1149-54. DOI PubMed

61. Longhi MS, Ma Y, Mieli-Vergani G, Vergani D. Aetiopathogenesis of autoimmune hepatitis. J Autoimmun 2010;34:7-14. DOI PubMed

62. Prados E, Cuervas-Mons V, de la Mata M, et al. Outcome of autoimmune hepatitis after liver transplantation. Transplantation 1998;66:1645-50. DOI PubMed

63. Milkiewicz P, Hubscher SG, Skiba G, Hathaway M, Elias E. Recurrence of autoimmune hepatitis after liver transplantation. Transplantation ; 1999:253-6. DOI

64. Czaja AJ. The immunoreactive propensity of autoimmune hepatitis: is it corticosteroid-dependent after liver transplantation? Liver Transpl Surg 1999;5:460-3. DOI PubMed

65. Krishnamoorthy TL, Miezynska-Kurtycz J, Hodson J, et al. Longterm corticosteroid use after liver transplantation for autoimmune hepatitis is safe and associated with a lower incidence of recurrent disease. Liver Transpl 2016;22:34-41. DOI PubMed

66. Montano-Loza AJ, Mason AL, Ma M, Bastiampillai RJ, Bain VG, Tandon P. Risk factors for recurrence of autoimmune hepatitis after liver transplantation. Liver Transpl 2009;15:1254-61. DOI PubMed

67. Ayata G, Gordon FD, Lewis WD, et al. Liver transplantation for autoimmune hepatitis: A long-term pathologic study. Hepatology 2000;32:185-92. DOI PubMed

68. Duclos-Vallée J-C, Sebagh M, Rifai K, et al. A 10 year follow up study of patients transplanted for autoimmune hepatitis: histological recurrence precedes clinical and biochemical recurrence. Gut 2003;52:893-7. DOI PubMed PMC

69. Doran TJ, Geczy AF, Painter D, et al. A large, single center investigation of the immunogenetic factors affecting liver transplantation. Transplantation;2000:1491-8. DOI PubMed

70. Neumann UP, Guckelberger O, Langrehr JM, et al. Impact of human leukocyte antigen matching in liver transplantation. Transplantation 2003;75:132-7. DOI PubMed

71. Balan V, Ruppert K, Demetris AJ, et al. Long-term outcome of human leukocyte antigen mismatching in liver transplantation: results of the National Institute of Diabetes and Digestive and Kidney Diseases Liver Transplantation Database. Hepatology 2008;48:878-88. DOI PubMed

72. Gelson W, Hoare M, Dawwas MF, Vowler S, Gibbs P, Alexander G. The pattern of late mortality in liver transplant recipients in the 
United Kingdom. Transplantation 2011;91:1240-4. DOI PubMed

73. Rowe IA, Webb K, Gunson BK, Mehta N, Haque S, Neuberger J. The impact of disease recurrence on graft survival following liver transplantation: a single centre experience. Transpl Int 2008;21:459-65. DOI PubMed

74. Kerkar N, Dugan C, Rumbo C, et al. Rapamycin Successfully Treats Post-Transplant Autoimmune Hepatitis. Am J Transplant ;2005:1085-9. DOI PubMed

75. Kaplan MM, Gershwin ME. Primary biliary cirrhosis. N Engl J Med 2005;353:1261-73. DOI PubMed

76. Poupon R. Primary biliary cirrhosis: a 2010 update. J Hepatol 2010;52:745-58. DOI PubMed

77. Joplin R, Gershwin ME. Ductular expression of autoantigens in primary biliary cirrhosis. Semin Liver Dis 1997;17:97-103. DOI PubMed

78. Hirschfield GM, Chapman RW, Karlsen TH, Lammert F, Lazaridis KN, Mason AL. The genetics of complex cholestatic disorders. Gastroenterology 2013;144:1357-74. DOI PubMed PMC

79. Hirschfield GM, Liu X, Xu C, et al. Primary biliary cirrhosis associated with HLA, IL12A, and IL12RB2 variants. N Engl J Med 2009;360:2544-55. DOI PubMed PMC

80. Mason AL. Is PBC a viral infectious disease? Best Pract Res Clin Gastroenterol 2018;34-35:27-39. DOI PubMed

81. Xu L, Shen Z, Guo L, Fodera B. Does a betaretrovirus infection trigger primary biliary cirrhosis? Proc Natl Acad Sci U S A 2003;100:8454-9. DOI PubMed PMC

82. Lammers WJ, van Buuren HR, Hirschfield GM, et al. Levels of alkaline phosphatase and bilirubin are surrogate end points of outcomes of patients with primary biliary cirrhosis: an international follow-up study. Gastroenterology 2014;147:1338-49.e5; quiz e15. DOI PubMed

83. Corpechot C, Chazouillères O, Rousseau A, et al. A Placebo-Controlled Trial of Bezafibrate in Primary Biliary Cholangitis. $N$ Engl $J$ Med 2018;378:2171-81. DOI PubMed

84. Lindor KD, Bowlus CL, Boyer J, Levy C, Mayo M. Primary biliary cholangitis: 2018 practice guidance from the American Association for the study of liver diseases. Hepatology 2019;69:394-419. DOI PubMed

85. Montano-Loza AJ, Corpechot C. Definition and Management of Patients With Primary Biliary Cholangitis and an Incomplete Response to Therapy. Clin Gastroenterol Hepatol 2020:S1542-3565(20)30926. DOI PubMed

86. Nevens F, Andreone P, Mazzella G, et al. A placebo-controlled trial of obeticholic acid in primary biliary cholangitis. N Engl J Med 2016;375:631-43. DOI PubMed

87. Lee J, Belanger A, Doucette JT, Stanca C, Friedman S, Bach N. Transplantation trends in primary biliary cirrhosis. Clin Gastroenterol Hepatol 2007;5:1313-5. DOI PubMed

88. Harms MH, Janssen QP, Adam R, et al. Trends in liver transplantation for primary biliary cholangitis in Europe over the past three decades. Aliment Pharmacol Ther 2019;49:285-95. DOI PubMed PMC

89. Goet JC, Harms MH, Carbone M, Hansen BE. Risk stratification and prognostic modelling in primary biliary cholangitis. Best Pract Res Clin Gastroenterol 2018;34-35:95-106. DOI PubMed

90. Neuberger J. Liver transplantation for primary biliary cirrhosis. Autoimmun Rev 2003;2:1-7. DOI PubMed

91. Carbone M, Neuberger J. Liver transplantation in PBC and PSC: indications and disease recurrence. Clin Res Hepatol Gastroenterol 2011;35:446-54. DOI PubMed

92. Nevens F. PBC-transplantation and disease recurrence. Best Pract Res Clin Gastroenterol 2018;34-35:107-11. DOI PubMed

93. Gross CR, Malinchoc M, Kim WR, et al. Quality of life before and after liver transplantation for cholestatic liver disease. Hepatology 1999;29:356-64. DOI PubMed

94. Abraham SC, Kamath PS, Eghtesad B, Demetris AJ, Krasinskas AM. Liver transplantation in precirrhotic biliary tract disease: Portal hypertension is frequently associated with nodular regenerative hyperplasia and obliterative portal venopathy. Am J Surg Pathol 2006;30:1454-61. DOI PubMed

95. Kashyap R, Safadjou S, Chen R, et al. Living donor and deceased donor liver transplantation for autoimmune and cholestatic liver diseases--an analysis of the UNOS database. J Gastrointest Surg 2010;14:1362-9. DOI PubMed

96. Khettry U, Anand N, Faul PN, et al. Liver transplantation for primary biliary cirrhosis: a long-term pathologic study. Liver Transpl 2003;9:87-96. DOI PubMed

97. Sylvestre PB, Batts KP, Burgart LJ, Poterucha JJ, Wiesner RH. Recurrence of primary biliary cirrhosis after liver transplantation: Histologic estimate of incidence and natural history. Liver Transpl 2003;9:1086-93. DOI PubMed

98. Abraham SC, Poterucha JJ, Rosen CB, Demetris AJ, Krasinskas AM. Histologic abnormalities are common in protocol liver allograft biopsies from patients with normal liver function tests. Am J Surg Pathol 2008;32:965-73. DOI PubMed

99. Demetris AJ, Markus BH, Esquivel C, et al. Pathologic analysis of liver transplantation for primary biliary cirrhosis. Hepatology 1988;8:939-47. DOI PubMed PMC

100. Montano-Loza AJ, Hansen BE, Corpechot C, et al. Factors Associated With Recurrence of Primary Biliary Cholangitis After Liver Transplantation and Effects on Graft and Patient Survival. Gastroenterology 2019;156:96-107.e1. DOI PubMed

101. Water JV de, Van de Water J, Gerson LB, et al. Immunohistochemical evidence of disease recurrence after liver transplantation for primary biliary cirrhosis. Hepatology;1996:1079-84. DOI PubMed

102. Robertson H, Kirby JA, Yip WW, Jones DEJ, Burt AD. Biliary epithelial-mesenchymal transition in posttransplantation recurrence of primary biliary cirrhosis. Hepatology 2007;45:977-81. DOI PubMed

103. Shackel NA, McGuinness PH, Abbott CA, Gorrell MD, McCaughan GW. Identification of novel molecules and pathogenic pathways in primary biliary cirrhosis: cDNA array analysis of intrahepatic differential gene expression. Gut 2001;49:565-76. DOI PubMed PMC 
104. Morioka D, Egawa H, Kasahara M, et al. Impact of human leukocyte antigen mismatching on outcomes of living donor liver transplantation for primary biliary cirrhosis. Liver Transpl 2007;13:80-90. DOI PubMed

105. Hashimoto T, Sugawara Y, Makuuchi M. Impact of human leukocyte antigen mismatching on outcomes of living donor liver transplantation for primary biliary cirrhosis. Liver Transpl;2007:938-9. DOI PubMed

106. Guy JE, Qian P, Lowell JA, Peters MG. Recurrent primary biliary cirrhosis: peritransplant factors and ursodeoxycholic acid treatment post-liver transplant. Liver Transpl 2005;11:1252-7. DOI PubMed PMC

107. Sanchez EQ, Levy MF, Goldstein RM, et al. The changing clinical presentation of recurrent primary biliary cirrhosis after liver transplantation. Transplantation 2003;76:1583-8. DOI PubMed

108. Carbone M, Mells GF, Alexander GJ, et al. Calcineurin inhibitors and the IL12A locus influence risk of recurrent primary biliary cirrhosis after liver transplantation. Am J Transplant 2013;13:1110-1. DOI PubMed

109. Silveira MG, Talwalkar JA, Lindor KD, Wiesner RH. Recurrent primary biliary cirrhosis after liver transplantation. Am J Transplant 2010;10:720-6. DOI PubMed

110. Neuberger J, Gunson B, Hubscher S, Nightingale P. Immunosuppression affects the rate of recurrent primary biliary cirrhosis after liver transplantation. Liver Transpl 2004;10:488-91. DOI PubMed

111. Montano-Loza AJ, Wasilenko S, Bintner J, Mason AL. Cyclosporine A inhibits in vitro replication of betaretrovirus associated with primary biliary cirrhosis. Liver Int 2010;30:871-7. DOI PubMed

112. Garcia RF, Evangelista Garcia C, McMaster P, Neuberger J. Transplantation for primary biliary cirrhosis: retrospective analysis of 400 patients in a single center. Hepatology 2001;33:22-7.

113. Montano $\square$ Loza AJ, Wasilenko S. Cyclosporine A protects against primary biliary cirrhosis recurrence after liver transplantation. $\mathrm{Am}$ J Transplant 2010;10:852-8. DOI PubMed

114. Charatcharoenwitthaya P, Pimentel S, Talwalkar JA, et al. Long-term survival and impact of ursodeoxycholic acid treatment for recurrent primary biliary cirrhosis after liver transplantation. Liver Transpl 2007;13:1236-45. DOI PubMed

115. Corpechot $\mathrm{C}$, Chazouillères $\mathrm{O}$, Belnou $\mathrm{P}$, et al. Long-term impact of preventive UDCA therapy after transplantation for primary biliary cholangitis. J Hepatol 2020;73:559-65. DOI PubMed

116. Gochanour E, Jayasekera C, Kowdley K. Primary sclerosing cholangitis: epidemiology, genetics, diagnosis, and current management. Clin Liver Dis 2020;15:125-8. DOI PubMed PMC

117. Hirschfield GM, Karlsen TH, Lindor KD, Adams DH. Primary sclerosing cholangitis. Lancet 2013;382:1587-99. DOI PubMed

118. Chapman R, Fevery J, Kalloo A, et al. Diagnosis and management of primary sclerosing cholangitis. Hepatology 2010;51:660-78. DOI PubMed

119. Lindor KD, Kowdley KV, Harrison ME, American College of Gastroenterology. ACG Clinical guideline: primary sclerosing cholangitis. Am J Gastroenterol 2015;110:646-59; quiz 660. DOI PubMed

120. Loftus EV Jr, Harewood GC, Loftus CG, et al. PSC-IBD: a unique form of inflammatory bowel disease associated with primary sclerosing cholangitis. Gut 2005;54:91-6. DOI PubMed PMC

121. Lamberts LE, Janse M, Haagsma EB, van den Berg AP, Weersma RK. Immune-mediated diseases in primary sclerosing cholangitis. Dig Liver Dis 2011;43:802-6. DOI PubMed

122. Melum E, Franke A, Schramm C, et al. Genome-wide association analysis in primary sclerosing cholangitis identifies two non-HLA susceptibility loci. Nat Genet 2011;43:17-9. DOI PubMed PMC

123. Liu JZ, Hov JR, Folseraas T, et al. Dense genotyping of immune-related disease regions identifies nine new risk loci for primary sclerosing cholangitis. Nat Genet 2013;45:670-5. DOI PubMed PMC

124. Brommé U, Grunewald J, Scheynius A, Olerup O, Hultcrantz R. Preferential V $\beta 3$ usage by hepatic T lymphocytes in patients with primary sclerosing cholangitis. J Hepatol;1997:527-34. DOI PubMed

125. Rea DJ, Heimbach JK, Rosen CB, et al. Liver transplantation with neoadjuvant chemoradiation is more effective than resection for hilar cholangiocarcinoma. Ann Surg 2005;242:451-8; discussion 458. DOI PubMed PMC

126. Mamari S, Djordjevic J, Halliday JS, Chapman RW. Improvement of serum alkaline phosphatase to $<1.5$ upper limit of normal predicts better outcome and reduced risk of cholangiocarcinoma in primary sclerosing cholangitis. J Hepatol 2013;58:329-34. DOI PubMed

127. Polanco NA, Levy C, Martin EF. Cholestatic Liver Diseases After Liver Transplant. Clin Liver Dis 2017;21:403-20. DOI PubMed

128. Vera A, Moledina S, Gunson B, et al. Risk factors for recurrence of primary sclerosing cholangitis of liver allograft. Lancet 2002;360:1943-4. DOI PubMed

129. Ravikumar R, Tsochatzis E, Jose S, et al. Risk factors for recurrent primary sclerosing cholangitis after liver transplantation. $J$ Hepatol 2015;63:1139-46. DOI PubMed

130. Bajer L, Slavcev A, Macinga P, et al. Risk of recurrence of primary sclerosing cholangitis after liver transplantation is associated with de novo inflammatory bowel disease. World J Gastroenterol 2018;24:4939-49. DOI PubMed PMC

131. Alexander J, Lord JD, Yeh MM, Cuevas C, Bakthavatsalam R, Kowdley KV. Risk factors for recurrence of primary sclerosing cholangitis after liver transplantation. Liver Transpl 2008;14:245-51. DOI PubMed

132. Moncrief KJ, Savu A, Ma MM, Bain VG, Wong WW, Tandon P. The natural history of inflammatory bowel disease and primary sclerosing cholangitis after liver transplantation--a single-centre experience. Can J Gastroenterol 2010;24:40-6. DOI PubMed PMC

133. Visseren T, Darwish Murad S. Recurrence of primary sclerosing cholangitis, primary biliary cholangitis and auto-immune hepatitis after liver transplantation. Best Pract Res Clin Gastroenterol 2017;31:187-98. DOI PubMed

134. Steenstraten IC, Sebib Korkmaz K, Trivedi PJ, et al. Systematic review with meta-analysis: risk factors for recurrent primary sclerosing cholangitis after liver transplantation. Aliment Pharmacol Ther 2019;49:636-43. DOI PubMed PMC 
135. Chen C, Ke R, Yang F, et al. Risk factors for recurrent autoimmune liver diseases after liver transplantation: a meta-analysis. Medicine 2020;99:e20205. DOI PubMed PMC 